\title{
Editorial
}

\section{Creating and Managing Change: Some Controversy, Some Level-Headedness}

\begin{abstract}
"We are being swept downstream by a torrent of change. The familiar vanishes and we have shifted into the rapids without really noticing them. Some people are acting as if they are still on a slowrunning river; others recognize that they are surrounded by white water." Robert Theobald ${ }^{1}$
\end{abstract}

Many writers have said that the only constant in our society may be change. Furthermore, we are often reminded that when the only certainty is dramatic, unpredictable change, we can no longer rely on what worked in academic libraries in the past to be the best approach in the future. To extend the above perspective by Theobald, are we librarians arriving at a point where we cannot predict our course through the rapids and are beginning to see rocks appearing ahead? On the contrary, I believe we should not perceive the transformation of academic and research libraries through the eyes of an alarmist!

Unquestionably, the rate of change is occurring faster today than ever before in the history of academic libraries. The academic library was begun in a much simpler time, a time when most knowledge was printed in books and the creation of new knowledge was less overwhelming. Today, the academic library must strive for greater relevance on its campus and take its responsibility for information dissemination more seriously.

\section{Technology: A Powerful Lever for Change}

It is difficult to quibble with the observation that technology has improved the human condition in general and, specifically, the effective-

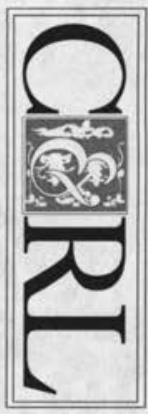
ness of libraries. Technology has significantly improved the performance of libraries! It has played a greater role in creating and implementing change in libraries than in any other dimension of our volatile culture. One of the obvious benefits derived from modern technology is the improvement in users' information access. Owing to sophisticated technology, users can now access intellectual resources held in various libraries throughout the world. Greater user selfsufficiency is certainly a dividend realized from library technology. Technology has made it possible for academic librarians to become a much greater "integral" part of the academic enterprise. Valueadded components derived from new technology are undoubtedly enabling the library to become the centerpiece of the campus.

At the same time libraries are becoming more accountable in their responsibility to disseminate information. Longstanding values are being revisited and reconsidered where necessary. New jobs are being created and long-existing jobs are being evaluated and sometimes dissolved. Technology is enabling us to break out of old thought patterns and develop a whole new way of thinking and responding.

The worldwide networked interchange perpetuated by an emerging global information infrastructure will initially have a subtle impact on smaller academic libraries but will eventually result in a huge influence on all academic libraries. The internationalization of scholar- 
ship will call for new approaches in collection development, different staffing patterns, and new collaborative endeavors. Creating and sharing digitized collections will significantly enhance the scholarly communication process. All of these changes are bringing new challenges and opportunities for creating and delivering better library services.

\section{Discontinuous Change}

Change is different now than it was in the past; for example, change is discontinuous and not part of a pattern. This new characteristic of change makes the librarian's planning process much more trying. However, the word "change" designates one of the most conspicuous and pervasive features of our sensory and introspective experiences - only the related feature of plurality is equally so. Due to the complexities of change, we are witnessing more efforts toward libraries becoming "learning organizations." A bona fide learning organization is one that learns and wants its people to learn. With unlimited opportunities for change, the library must continually expand its capacity to create its own future.

\section{Upside-Down Thinking}

Libraries have a tendency to change gradually and prudently. Academic librarians have not been encouraged to take significant risks for several reasons, including limited financial resources. Change, for its own sake, has been viewed as leading only to a type of dysfunctionalism in libraries that reduces their effectiveness or equilibrium. Since more discontinuous change is being encouraged, should not more emphasis be placed on upside-down thinking? This type of thinking would include looking at library practices and issues from back to front, inside-out, or upside-down. Such thinking would stimulate our imaginations or spur our creativity.

Some libraries have already deviated from the normal way of doing things. For example, libraries have been outsourcing some of their activities (e.g., technical services), more of the acquisitions' budget is being used for site licenses and electronic formats, and some libraries are employing more part-time staff. We can indulge in some upside-down thinking by asking questions such as: Will the academic library become less "place centric" but more "user centric"? How soon will libraries permit more of their staff to work (telecommute) from their homes? How soon can we expect a larger mix of information technologists and librarians? When will we finally come to our senses and determine a library's worth and effectiveness on factors other than the size of its inventory and the capacity to identify items within it? In these uncertain times we should not be modifying or recycling all of the conventional wisdom that worked in a bygone era.

\section{Moving from Passive to Aggressive}

When traditions solidify, vitality diminishes and creativity fades. Today's effective library must embrace creativity, innovation, and entrepreneurship. And it must provide an environment that encourages and supports risk taking! In the viable library, there is our inherent responsibility to calculate strategies appropriate to existing and anticipated external and internal factors. Libraries cannot remain predominantly passive institutions. Those of us who work in libraries should step up to our responsibility in improving their effectiveness. We should recognize that technology can be a dominant driving force of change. Via technology, we have the opportunity to reconstruct library services that will be more resourceful for current and future users. Notwithstanding the discomfort, anxiety, and stress brought forth by change, libraries are expected to continue refinement and improvement. Radical changes in libraries are becoming more the norm than the uncommon. The preparation, timing, and strategies associated with making 
changes are paramount. Thus, it is fitting to end this discussion with a surfing metaphor: "the time to change is when you don't have to; when you're on the crest of the wave, not when you're in the trough."2

\section{DONALD E. RIGGS}

\section{Notes}

1. Robert Theobald, The Rapids of Change: Social Entrepreneurship in Turbulent Times (Indianapolis: Knowledge Systems, 1987), 11.

2. Robert J. Kriegel and Louis Patler, If It Ain't Broke ... Break It! And Other Unconventional Wisdom for a Changing Business World (New York: Warner Books, 1991), 5.

\section{NEW for Academic Libraries!}

\section{Humanistic Management \\ by Teamwork:}

An Organizational and Administrative

Alternative for Academic Libraries

David A. Baldwin and

\section{Robert LaLiberte Migneault}

Discover a dynamic new leadership paradigm that will help you meet the challenges of the future. This book includes an overview, guidelines, examples, and bibliographies of further resources for study.

1996 xvi, 187p. ISBN 0-87287-981-X

$\$ 35.00$

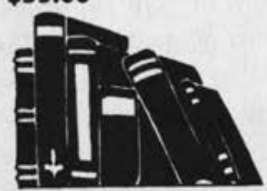

The Academic Librarian's

Human Resources Handbook:

Employer Rights and Responsibilities

David A. Baldwin

This handbook offers you "how to" information on academic library management and provides a single, up-to-date source for laws, regulations, executive orders, guidelines, and court decisions on employee and employer rights and responsibilities. A must buy!

1996 ca.175p. ISBN 1-56308-345-0 $\$ 28.50$

\section{Resources from} Libraries Unlimited 